\title{
Author Correction: Engineered commensal microbes for diet-mediated colorectal-cancer chemoprevention
}

Chun Loong Ho, Hui Qing Tan, Koon Jiew Chua, Aram Kang, Kiat Hon Lim, Khoon Lin Ling, Wen Shan Yew, Yung Seng Lee (D, Jean Paul Thiery and Matthew Wook Chang (D)

Correction to: Nature Biomedical Engineering https://doi.org/10.1038/s41551-017-0181-y, published 10 January 2018.

In the version of this Article originally published, panels $\mathbf{b}$ and $\mathbf{c}$ of Fig. 5 should have been swapped; that is, Fig. $5 \mathrm{c}$ should have been Fig. 5b, and vice versa. This has now been rectified and the corrected figure is shown below. 


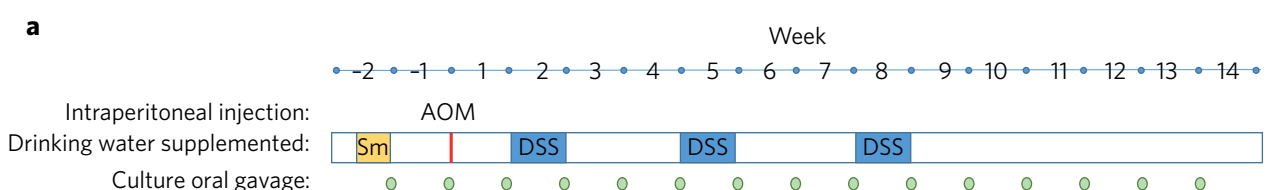

b
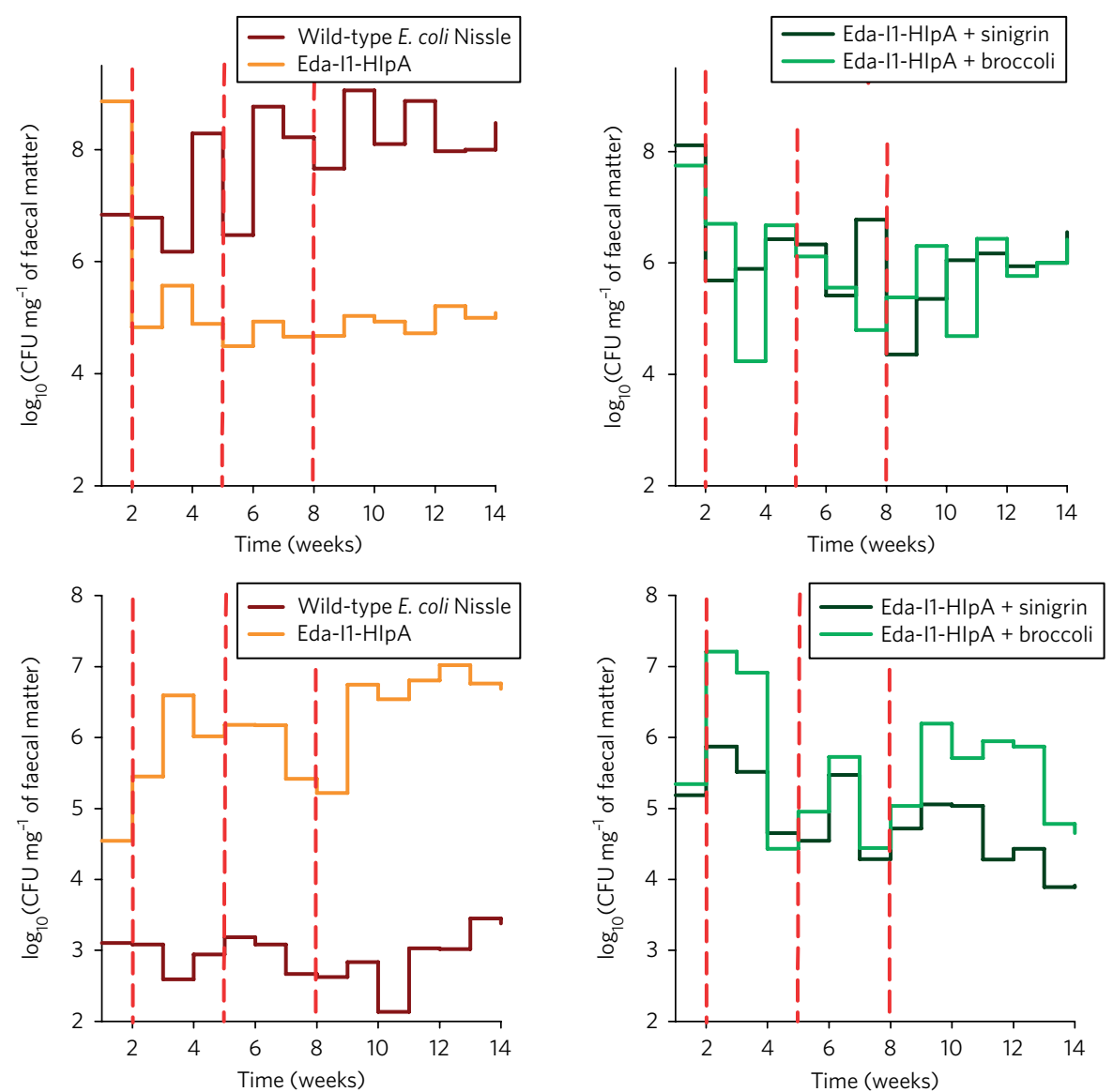

d

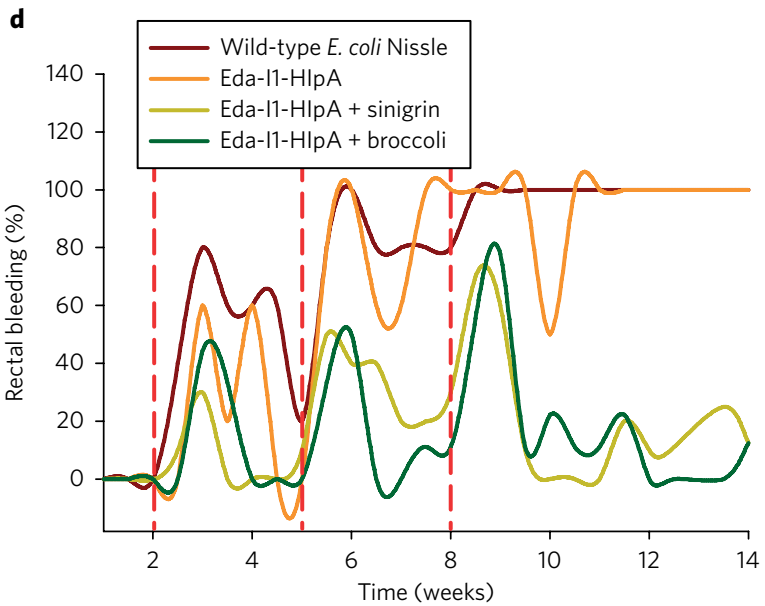

Fig. $\mathbf{5}$ | b,c | Corrected.

Published online: 16 June 2020

https://doi.org/10.1038/s41551-020-0580-3 